\title{
Monsoonal Reversal of Remote Sensing Biases in Latent Heat Flux over the Eastern Arabian Sea
}

\author{
P.M.Muraleedharan, T. Pankajakshan, P.V.Sathe, V.S.N. Murty and "K.R. Santosh \\ National Institute of Oceanography, Goa 403 004, India \\ *Dept. of Atmospheric Sciences, Cochin University of Science \& Technology, Kochi 682 016, India
}

\begin{abstract}
The Arabian Sea is a unique basin where a number of atmospheric and oceanographic processes occur due to the contrasting climatic conditions, which it experiences. The drastic monsoonal variability occurring in the boundary layer adversely affects the quality of remote sensing data and derived products. Comparisons of satellitebased estimate of Latent Heat Flux (LHF) with in situ values demonstrate the nature and extent of such variabilities. Mean satellite fluxes underestimate in situ values during summer (July to September) and overestimate them during fall (October to November). The underestimation peaked for high LHF values and disappeared for low LHF during summer. During fall, maximum over-estimation occurred when the LHF values were relatively low and it disappeared for higher LHF. These observations closely followed the behavior of satellite biases of sea surface temperature (SST) and wind speed (WS) during the two contrasting periods. Biases of SST and WS indicated opposite trends on either side of a threshold of $28.5^{\circ} \mathrm{C}$ and $5 \mathrm{~m} / \mathrm{s}$, respectively.
\end{abstract}

Key words : Validation, Air-sea Interaction, Bias, Indian Ocean, Latent Heat Flux, Time variation. 


\section{Introduction}

The last few decades had witnessed the emergence of remote sensing technology and several well-calibrated multi-sensor data are now available for computing air-sea fluxes. Efforts had also been made to refine the bulk method to reduce the uncertainty from a 25-30 \% level to the acceptable limit. One such effort led to the launching of the Coupled Ocean-Atmosphere Response Experiment (COARE) in 1992 to develop an efficient bulk parameterization algorithm [Fairall et al., 1996; Bradley et al., 2000]. More recently, Fairall et al. [2003] have come up with an improved version of COARE algorithm (COARE_3.0 version) that could reduce the uncertainty to 5\% level for wind speeds less than $10 \mathrm{~m} / \mathrm{s}$ and to $10 \%$ for wind speeds between 10 and $20 \mathrm{~m} / \mathrm{s}$. Solar radiation and latent heat flux are the two major components of the heat balance equation, with the former heating up the ocean while the latter cools it down. Solar heating is largely limited by vapor bearing clouds while the latent heat loss is controlled by several factors such as wind speed, sea surface temperature and the boundary layer humidity gradient $\left(\mathrm{q}_{\mathrm{s}}-\mathrm{q}_{\mathrm{a}}\right)$. Since the Indian Ocean experiences several contrasting seasons with distinct atmospheric and oceanographic processes as discussed earlier [Thadathil and Gosh (1992), Prasanna Kumar et al. (2000 \& 2002), Bhat (2003), Shankar et al., (2004)],

it is an ideal test ground for analyzing various combinations of the parameters to study the effect of their mutual interactions. Through the present study, long-term time series measurements of all surface meteorological parameters adequate to address the air-sea exchange processes are now available for the first time over the northern basin. The study would also lead to the understanding of boundary layer dynamics and their role in modifying remotely sensed data during contrasting climatic conditions.

\section{Data and Method}

Wind speed, air temperature, relative humidity, incoming solar radiation and atmospheric pressure were measured every $30 \mathrm{~min}$ from July to November 2000 by an autonomous weather station (AWS) installed at the island station situated on the southwest coast of India $\left(10.5^{\circ} \mathrm{N} ; 72^{\circ} \mathrm{E}\right)$ (Table 1). The coral island is positioned diagonally in the NE to $\mathrm{SW}$ direction. It is $5 \mathrm{~km}$ long and $1.5 \mathrm{~km}$ wide at the north, tapering to $0.5 \mathrm{~km}$ southward. It is situated more than $3 \mathrm{~km}$ away from the mainland. The 
facility has been established as part of the IRS-P4 (Indian Remote Sensing Satellite) validation mission [Muraleedharan et al., 2004]. Validation results have indicated that the island-based measurements are representative of open ocean conditions and that platforms from the mainland are far enough to minimize land contamination in microwave bands.

Table 1. Autonomous Weather Station sensor specifications.

\begin{tabular}{|c|c|c|c|}
\hline Parameter & Sensor/Model & Accuracy/Error & Range \\
\hline Total solar Radiation & L1-2004A Pyranometer & $5 \%$ & $0-3000 \mathrm{Wm}^{-2}$ \\
\hline Pressure & $\begin{array}{l}\text { HoneyWell precision } \\
\text { Barometer }\end{array}$ & $\pm 0.8 \mathrm{mBar}$ & $500-1200 \mathrm{mBar}$ \\
\hline Relative Humidity & Rotronic Hygrometer C94 & $\pm 1 \%$ at $20^{\circ} \mathrm{C}$ & $0-100 \%$ \\
\hline Air Temperature & Rotronic Pt100 RTD & $\pm 0.2^{\circ} \mathrm{C}$ & -40 to $60^{\circ} \mathrm{C}$ \\
\hline Wind Speed & $\begin{array}{l}\text { Young Model } \\
05103 \text { wind monitor }\end{array}$ & $\pm 0.3 \mathrm{~m} / \mathrm{s}$ & 0 to $60 \mathrm{~m} / \mathrm{s}$ \\
\hline
\end{tabular}

Three-hourly sea surface temperature (SST) data were obtained from the moored buoy (MB) deployed $\left(10.5^{\circ} \mathrm{N} ; 72.5^{\circ} \mathrm{E}\right)$ close to this island station. Care has been taken to ensure that there are no random errors in the in situ data. The offshoots are discarded in the initial stages of the data processing. Daily rainfall data were also procured from the meteorological observatory at Amini Island $\left(11^{\circ} \mathrm{N} ; 72.5^{\circ} \mathrm{E}\right)$ situated very close to the above observational platforms. The monthly mean climatology of down-welling longwave radiation has been computed from Langley's SRB tapes in place of daily values (Darnel et al., 1992). The state of the art COARE_3 bulk parameterization algorithm [Fairall et al., 2003] was then used to compute latent heat flux (LHF) using the above set of sea truth parameters to minimize the uncertainty level.

Data from day and night passes of TRMM (Tropical Rainfall Measuring Mission) Microwave Imager (TMI) [wind speed (WS), columnar water vapour (CWP) and SST] and Special Sensor Microwave Imager (SSMI-F14) [WS and CWP] were analyzed from July to November 2000 to generate collocated data match-ups. TMI SSTs were used for the LHF computations from SSMI data. Near surface specific humidity $\left(\mathrm{q}_{\mathrm{a}}\right)$ was derived from columnar water vapour using the Liu and Niiler (1984) model. Air temperature $\left(T_{a}\right)$ was then derived from $\mathrm{q}_{\mathrm{a}}$ using polynomials constructed based on 15 years' surface 
meteorological data collected over the tropical Indian Ocean [Sathe and Muraleedharan, 1999]. Due to the wide temporal and spatial variation of $T_{a}$ over the Arabian Sea (18 to $38^{\circ} \mathrm{C}$; RMSD $=2.7^{\circ} \mathrm{C}$ ), fourteen polynomials were constructed by partitioning the Sea into various temporal and spatial domains so that RMSD could be reduced to $\sim 1{ }^{\circ} \mathrm{C}$ over central Arabian Sea from July to November. This was comparable to the values $\left(0.0^{\circ} \pm\right.$ $1.0^{\circ} \mathrm{C}$ ) obtained by Thadathil et al. (1993) over the Pacific and more robust than the values $\left(-0.3^{\circ} \pm 3.1^{\circ} \mathrm{C}\right)$ obtained by Konda and Imasato (1996) for monthly mean satellite data. The uncertainty in LHF computation was well within the limit of $2 \%$ even after assuming a constant pressure of $1013 \mathrm{hPa}$ and $\mathrm{T}_{\mathrm{a}}=\mathrm{SST}-1^{\circ} \mathrm{K}$ (Schulz et al, 1997). LHF computations using COARE_3 scheme were made for both day and night passes of TMIand SSMI- derived parameters by assuming no rainfall situations and a constant mean sea level pressure of $1008 \mathrm{mb}$ as recommended by Dr. Chris Fairall (personal communication). The COARE_3 bulk algorithm computes turbulent LHF (ef) and heat flux due to rainfall (rf) separately. Even if the rain rate is provided to the algorithm, only 'rf' value is affected while 'ef' remains unchanged. Since there are no reliable scanning radar measurements for in situ rainfall (from Ship and Aircraft) over the study area, we consider only the 'ef' computation. This is equivalent to the condition of 'no rainfall' in this study. It is to be noticed that there were only 20 days of strong rainfall events $(0.5-4$ $\mathrm{mm} / \mathrm{hr}$ ) out of the 150 days data used in this study, which amounts to only $14 \%$ of the total observation period. This suggests about $86 \%$ of no rainfall situation including southwest monsoon season. Shortwave and longwave radiative fluxes were used for the cool skin and warm layer correction for ocean temperature, whenever in situ temperatures were measured at a certain depth rather than at the interface. These inputs were ignored for satellite measurement of skin temperature. Daily, 3-day, 7-day and 30-day moving averages of all parameters were constructed for both observed and satellite derived values to facilitate inter-comparison.

\section{Results and Discussion}

Daily, 3-day, 7-day and 30-day moving averages of LHF generated from both satellite (TMI \& SSMI) as well as in situ data were compared and the results presented herein. Correlation during summer was remarkable for both TMI \& SSMI compared to 
that in fall (Fig.1; top panel). SSMI was marginally better correlated with the observed values than TMI in summer but the opposite was true during fall. During summer, mean bias (i.e., satellite minus in situ) was negative but the bias reversed in fall (Fig.1; bottom panel). In general, LHF values derived from TMI were closer to the observed values. Comparison of TMI-LHF against in situ values for three averaging periods (daily, 7-day and 30-day) during summer and fall are therefore presented for further analysis (Fig. 2). The mean negative and positive biases during summer and fall, respectively, implied that the satellite underestimated values during summer and overestimated them during fall inter-monsoon. The distribution of individual biases (residuals) exhibited negligibly small values for lower LHF and a more negative bias for higher LHF during summer (Fig.2; left panel). On the contrary, high positive biases were noticed with lower LHF during fall, which disappeared for higher LHF (Fig. 2; right panel). It was therefore considered worthwhile to analyze the basis for such a peculiar behavior of satellite retrievals over this basin.

\subsection{Inter-relationship of WS, SST, Dq and LHF during summer and fall}

Wind speed had a direct relationship with LHF (Fig.3a). The daily WS bias had an increasing and decreasing trend for WS below and above $5 \mathrm{~m} / \mathrm{s}$, respectively. The trends were derived from a linear-square fit applied to the scatter. A threshold wind speed of $5 \mathrm{~m} / \mathrm{s}$ was noticed, below which the satellite over-estimation increased with wind speed (Fig. 3b). However it decreased above $5 \mathrm{~m} / \mathrm{s}$ (Fig. 3c). The opposite nature of biases on either side of the threshold had imparted a curve-like appearance to the scatter, with residuals peaking close to the threshold wind speed of $5 \mathrm{~m} / \mathrm{s}$ (Fig. $3 \mathrm{~d}$ ).

The SST-LHF relationship was not straightforward as was with WS. Wallace [1992] suggested from thermodynamic consideration that at high SST the LHF would be enhanced, which would then cool the ocean. The Thermostat Hypothesis of Ramnathan and Collins (1992) and model results of Sui et al (1991) supported an inverse relationship between LHF and SST. Based on TOGA TAO buoy data Zhang and McPhaden [1995] observed that at SST below $300-301{ }^{\circ} \mathrm{K}$ the LHF increased with increasing SST. However at SST higher than $301^{\circ} \mathrm{K}$ the LHF deceased with increasing SST. The inverse relationship obtained in the present study is thus justified as the SST seldom dropped 
below $300{ }^{\circ} \mathrm{K}$ during this period (Fig.4a). Satellite bias during summer changed from negative to positive for SST variations from 27.5 to $29^{\circ} \mathrm{C}$ (Fig. $4 \mathrm{~b}$ ). The sliding of the bias from positive to negative for SSTs greater than $28.5^{\circ} \mathrm{C}$ characterized the fall intermonsoon season (Fig.4c). Satellite SST's were closer to the observed values near the threshold $\left(28.5^{\circ} \mathrm{C}\right)$ but were an underestimate of the in situ values on either side of this threshold, giving the scatter a curved appearance (Fig.4d).

The humidity gradient $\left(\mathrm{D}_{\mathrm{q}}\right)$ directly correlated with SST and inversely correlated with WS during the period of investigation. Satellite clearly underestimated the sea truth values of $\mathrm{D}_{\mathrm{q}}$ to produce negative bias for almost all situations (figure not given). However the trend of the bias during summer decreased only marginally with observed values while it had a similar opposite trend during fall.

\subsection{Seasonal reversal of satellite-LHF biases}

The daily LHF exhibited minimum satellite bias for low LHF and large negative bias for high LHF during summer (Fig. 2; left panel). Relatively high WS ( $>5 \mathrm{~m} / \mathrm{s})$ and low SST $\left(<29^{\circ} \mathrm{C}\right)$ generate high LHF while low WS $(<5 \mathrm{~m} / \mathrm{s})$ and high SST $\left(>28.5^{\circ} \mathrm{C}\right)$ support low LHF during summer by virtue of the inverse LHF-SST relationship. It has been shown that for higher WS $(>5 \mathrm{~m} / \mathrm{s})$ satellite overestimation reduces to near zero values (Fig.3c). Similarly for low SST $\left(<28.5^{\circ} \mathrm{C}\right)$ the satellite underestimation increases to a maximum of $1{ }^{\circ} \mathrm{C}$ (Fig. 4b). Therefore the satellite residuals in the high LHF zone are largely due to the enhanced SST bias as the LHF-SST relationship for SST $<28{ }^{\circ} \mathrm{C}$ is direct [Zhang and McPhaden, 1995]. In the low LHF zone (WS $<5 \mathrm{~m} / \mathrm{s}$; SST $>28.5^{\circ} \mathrm{C}$ ), WS overestimation reduces to a minimum while the SST bias becomes positive (Figs.3d \& 4b). Marginal overestimation of WS and SST effectively cancel each other in the process of generating LHF, as the LHF-SST relationship is inverse for SST $>28.5^{\circ} \mathrm{C}$. The disappearances of residuals in the low LHF sector during summer corroborate the above observations (Fig.2; left panel).

During fall the secondary heating commences in clear sky conditions and the mean temperature of the eastern Arabian Sea is above $28.5^{\circ} \mathrm{C}$. Weak winds $(<5 \mathrm{~m} / \mathrm{s})$ prevail over this basin during this season. Maximum and minimum LHF residuals were 
observed in the low and high LHF zones, respectively (Fig.2; right panel). Relatively high WS $(>2.5 \mathrm{~m} / \mathrm{s})$ and low SST $\left(<29^{\circ} \mathrm{C}\right)$ are instrumental in generating LHF during this season (Figs. $3 b$ \& 4c). Maximum satellite overestimation occurred in these ranges of WS while SST underestimation disappeared below $29{ }^{\circ} \mathrm{C}$ and the trend continued to show signs of overestimation (Fig. 4c). As the LHF-SST relationship is inverse in this range of temperature, the SST effect counters the WS effect in generating LHF. This would lead to minimum LHF residuals in the high LHF zone during the fall intermonsoon season. Similarly in the low LHF zone wind speeds are generally weak $(<2.5$ $\mathrm{m} / \mathrm{s})$ over the warm ocean $\left(>29{ }^{\circ} \mathrm{C}\right)$. Wind speed overestimation is minimum in this sector but the residuals are still positive (Fig. 3b). SST underestimation is also maximum for values above $29^{\circ} \mathrm{C}$. The cumulative effect supports the satellite to overestimate LHF by virtue the of inverse LHF-SST relationship.

\subsection{Bias analysis and recommendations}

Mean bias during summer and fall under various LHF ranges are presented for four averaging periods (Table 2). Biases are compared with mean observed LHF values at various ranges and the ratios are given in brackets as percentage. The uncertainty of computation of LHF from in situ data for WS $<10 \mathrm{~m} / \mathrm{s}$ (present case) is only $5 \%$ [Fairall et al., 2003] but the bias obtained under different LHF ranges appears to be higher than the computational uncertainty except for LHF below $80 \mathrm{Wm}^{-2}$ during summer. The additional bias may be due to the remote sensing uncertainty. The bias for LHF below 80 $\mathrm{Wm}^{-2}$ during summer is thus insignificant over the eastern Arabian Sea. It is worth noting that the percentages of mean LHF equivalent to the bias do not vary much except for the 30-day averaging period, although bias increases for higher LHF during summer. On the contrary both bias and the percentage equivalent to it below $80 \mathrm{Wm}^{-2}$ are high during fall and the measurements in these ranges are susceptible to errors. During fall, LHF biases corresponding to the observed values (ranges from 80 to $140 \mathrm{Wm}^{-2}$ ) are relatively higher than those obtained in summer. However the computation of LHF in these ranges is less robust than in summer and it is thus recommended to use such satellite derived flux values with caution. 
Table 2. Satellite biases under various ranges of LHF during two seasons. Numbers in brackets refer to bias given in terms of percentage of mean in situ LHF estimates. Stars $(* * *)$ denote no LHF values in these ranges.

\begin{tabular}{lcccccc}
\hline Seasons & $\begin{array}{l}\text { Range of LHF } \\
\left(\mathrm{W} / \mathrm{m}^{2}\right)\end{array}$ & \multicolumn{5}{c}{ Bias for various averaging periods } \\
& & Daily & 3 day & 7day & 30 day \\
\hline Summer & $<80$ & $-1.8(3)$ & $-2.1(3)$ & $-1.3(2)$ & $* * *$ \\
& $80-140$ & $-11.2(10)$ & $-13.6(12)$ & $-16.2(14)$ & $-29.8(18)$ \\
& $>140$ & $-15.3(10)$ & $-13.4(9)$ & $-18.3(13)$ & $* * *$ \\
Fall & $<80$ & $31.6(48)$ & $22.2(31)$ & $19.3(26)$ & $* * *$ \\
& $80-140$ & $18.9(19)$ & $19.7(21)$ & $17.5(19)$ & $13.9(16)$ \\
& $>140$ & $* * *$ & $* * *$ & $* * *$ & $* * *$ \\
\hline
\end{tabular}

\section{Summary}

Satellite derived LHFs convincingly underestimate in situ fluxes during summer over the eastern Arabian Sea and overestimate it during fall inter-monsoon season. The maximum negative and positive biases were noticed for higher and lower LHF values, respectively, during summer and fall. However the bias disappears in the lower and higher LHF domains during summer and fall, respectively. The monsoonal reversal of LHF biases stems from the fact that the satellite biases of wind speed and sea surface temperature exhibit opposite trends on either side of a certain threshold and the nature of the LHF bias strictly follows the cumulative effect of both WS and SST biases. The trend of residuals of wind speed and sea surface temperature with respect to the threshold identified dictates the nature of latent heat flux biases over the eastern Arabian Sea as it experiences contrasting climatic conditions during summer and fall. The peculiar behavior of these residuals would certainly have a significant influence on future validation exercises especially over this part of the basin.

Acknowledgements: We thank the Director, National Institute of Oceanography, Goa and The Director, Space Application Center, Ahmedabad for the facilities and funds to set up the Autonomous Weather Station at Lakshadweep Island. The efforts of Dr. Ismail Koya, Deputy Director, Science and Technology, Kavarathi, in collecting surface met data are gratefully acknowledged. We also thank Dr. Frank Wentz and his office 'Remote Sensing Systems' for providing SSMI and TMI products. 


\section{References}

Bhat, G.S (2003), Measurement of Air Sea fluxes over the Indian Ocean and the Bay of Bengal. J. Climate, 16, $767-775$.

Bradley, E.F., C.W. Fairall, J.E. Hare and A.A.Grachev (2000), An old and improved bulk algorithm for air-sea fluxes: COARE 2.6, A. Preprints, $14^{\text {th }}$ Symp. On Boundary Layer and Turbulence, Aspen, CO, Amer. Meteor. Soc., 294 - 296.

Darnell, W.L., W. Staylor, S.K.Gupta, N.A.Ritchey_and A.C. Wilber (1992), Seasonal variation of surface radiation budget derived from International Satellite Cloud Climatology Project C1 data. J. Geophys. Res., 97, 15741-15760.

Fairall, C.W., E.F. Bradley, D.P.Rogers, J.B. Edson and G.S.Young (1996), Bulk Parameterization of air-sea fluxes in TOGA COARE, J. Geophys. Res., 101, 3747 $-3767$.

Fairall, C.W., E.R. Bradley, J.E. Hare, A.A. Grachev and J.B.Edson (2003), Bulk Parameterization of Air-Sea Fluxes: Updates and verification for the COARE Algorithm, J. of Climate., 16, 571 - 591.

Liu, W.T. and P.P. Niiler (1984), Determination of monthly mean humidity in the atmospheric surface layer over ocean from satellite data, J. Phys. Oceanogr., $14,1451-1457$.

Konda, M and N. Imasato (1996), A new method to determine near-sea surface air temperature by using satellite data. J. Geophy. Res., 101, No. C6, 14,349 - 14360.

Muraleedharan, P.M., T. Pankajakshan, and M. Harikrishnan, M (2004), Validation of Multi-channel Scanning Microwave Radiometer on-board Oceansat-I. Curr. Sci., $87,370-376$.

Prasanna Kumar, S., M. Madhupratap, M. Dileep Kumar, M. Gauns, P.M.Muraleedharan, V.V.S.S. Sarma, and S.N. De Souza (2000), Physical control of primary productivity on a seasonal scale in central and eastern Arabian Sea, Proc. Indian Acad. Sci., 109, 433 - 441.

Prasanna Kumar, S., P.M. Muraleedharan, T.G. Prasad, M. Gauns, N. Ramiah, S.N. De Souza, S. Sardesai, and M. Madhupratap (2002), Why is the Bay of Bengal less productive during summer monsoon compared to the Arabian Sea? Geophys. Res. Ltt., 29(24), 2235, doi: 10.1029/2002GL016013.

Ramanathan, V.and W.Collins (1992), Thermostat and global warming. Nature, 357, 649.

Sathe, P.V., and P.M. Muraleedharan (1999), Retrieval of sea surface air temperature from Satellite data over Indian Ocean.: An empirical approach, Asian Meteorological Online Newsletter. Vol. 3, No.1 [http://weather.ou.edu/ spark/AMON/v3_nl]. 
Schluessel, P., L. Schanz and G. Englisch (1995), Retrieval of Latent Heat Flux and Longwave Irradiance at the sea surface from SSM/I and AVHRR measurements, Adv. Space Res., 16, (10)107-(10)116, 1995.

Schulz, J., J. Meywern, S. Ewald and P. Schlussel (1997), Evaluation of SatelliteDerived Latent Heat Fluxes. J. of Climate, 10, 2782 - 2795.

Shankar, D, V.V. Gopalakrishna, S.S.C. Shenoi, F. Durand, S.R. Shetye, C.K. Rajan, Z. Johnson, N. Araligidad_and G.S. Michael (2004), Observational evidence for | westward propagation of temperature inversions in the southeastern Arabian Sea, Geophys. Res. Lett., 31, L08305, doi:10.1029/2004GL019652.

Sui, C,-H., K,-M. Lau, and A.K. Betts (1991), An equilibrium model for the coupled ocean-atmosphere boundary layer in the Tropics, J. Geophys. Res., 96, 3151 3163.

Thadathil, P., Shikauchi, A., Sugimori, Y. and M. Kubota (1993), A statistical method to get surface level air temperature from Satellite Observations of Precipitable Water. J. of Oceanography, 49, $551-558$.

Thadathil, P. and A.K. Gosh (1992). Surface Layer Temperature Inversion in the Arabian Sea during winter. J. of Oceanogr., 48, 293 - 304.

Wallace, J.M. (1992), Effect of deep convection on the regulation of tropical sea surface temperature. Nature, 357, $230-231$.

Zhang, G.J. and M.J. McPhaden (1995), The relationship between Sea Surface Temperature and Latent Heat Flux in the Equatorial Pacific, J. of Climate., 8, 589 -605 . 


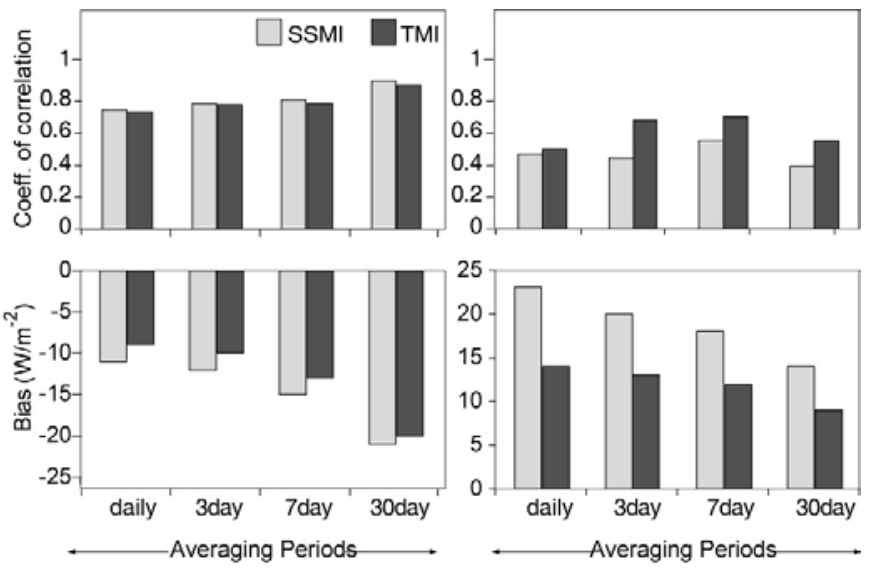

Fig. 1. Coefficient of correlation, and Bias between satellite and in situ based LHF values during summer (left panel) and fall (right panel). 

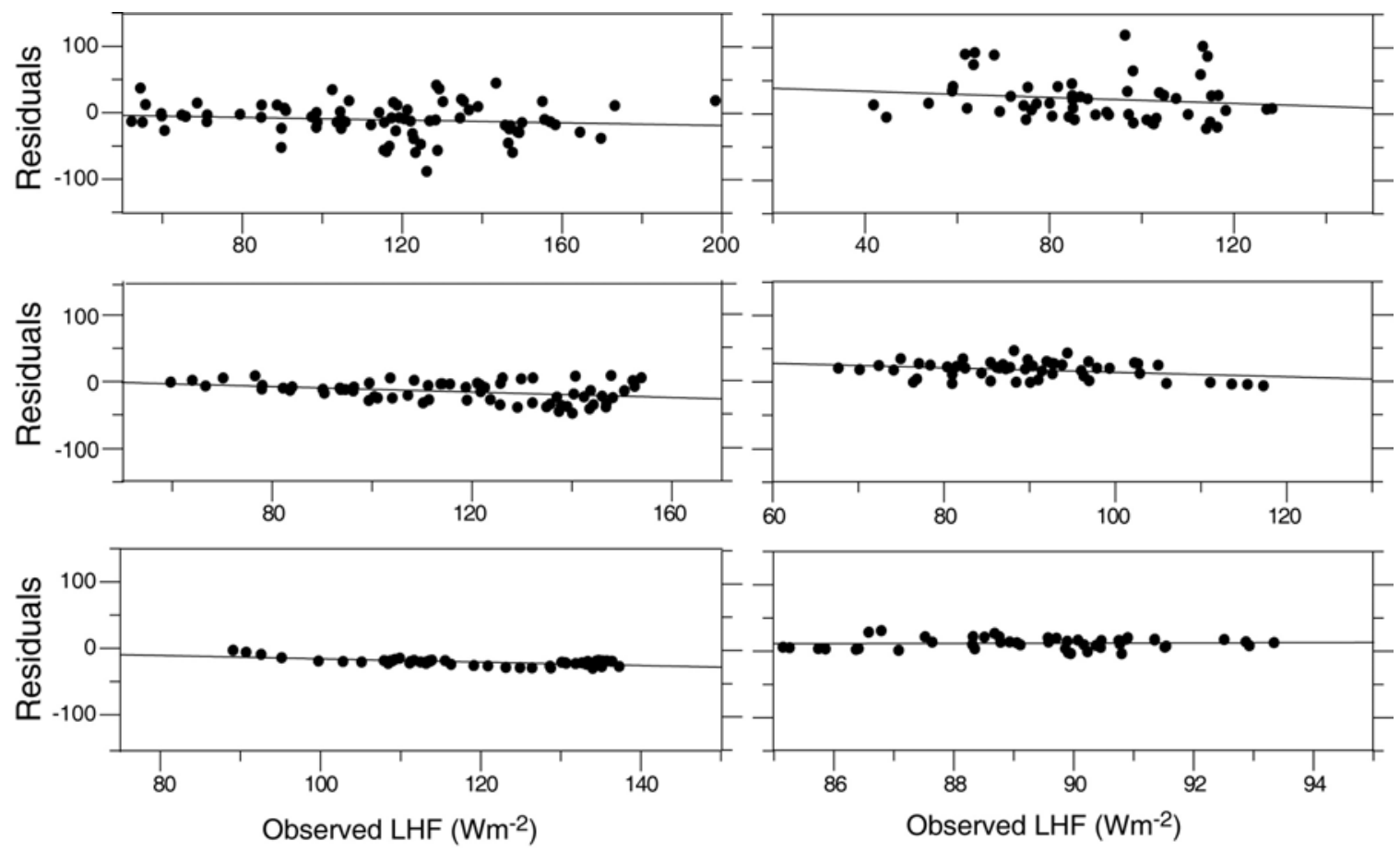

Fig. 2. Residuals are plotted against observed LHF values for daily (tope panel), 7 day (middle panel) and 30 day (bottom panel) moving averages. The left and right panels represent summer and fall respectively. 

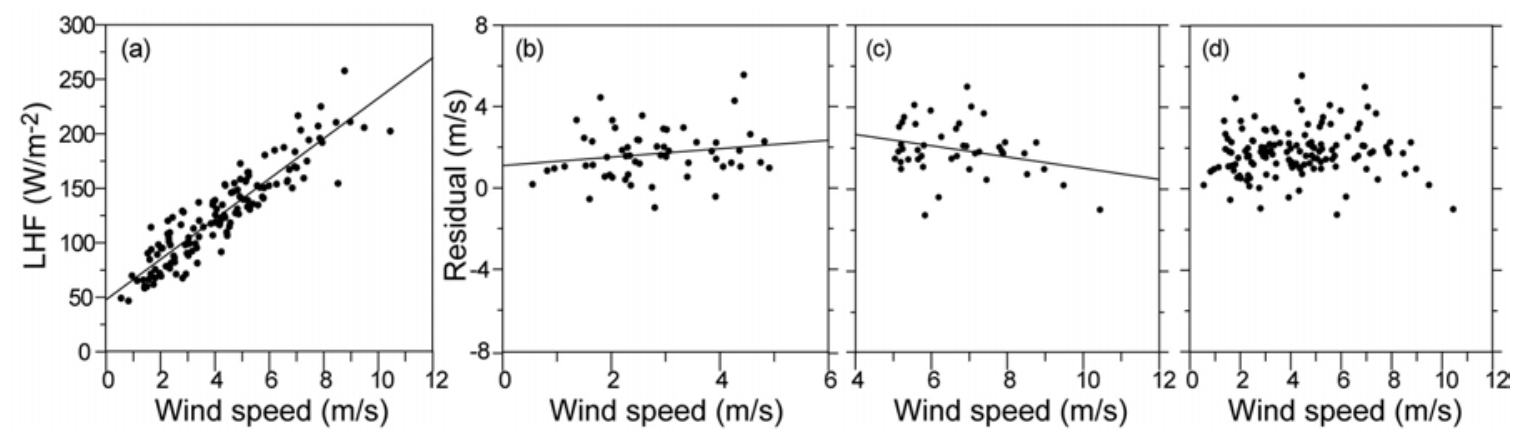

Fig.3. Scatter plots of WS Vs LHF (a). Residuals Vs WS for WS $<5 \mathrm{~m} / \mathrm{s}$ (b) for $\mathrm{WS}>5 \mathrm{~m} / \mathrm{s}$ (c) and for both situations (d).
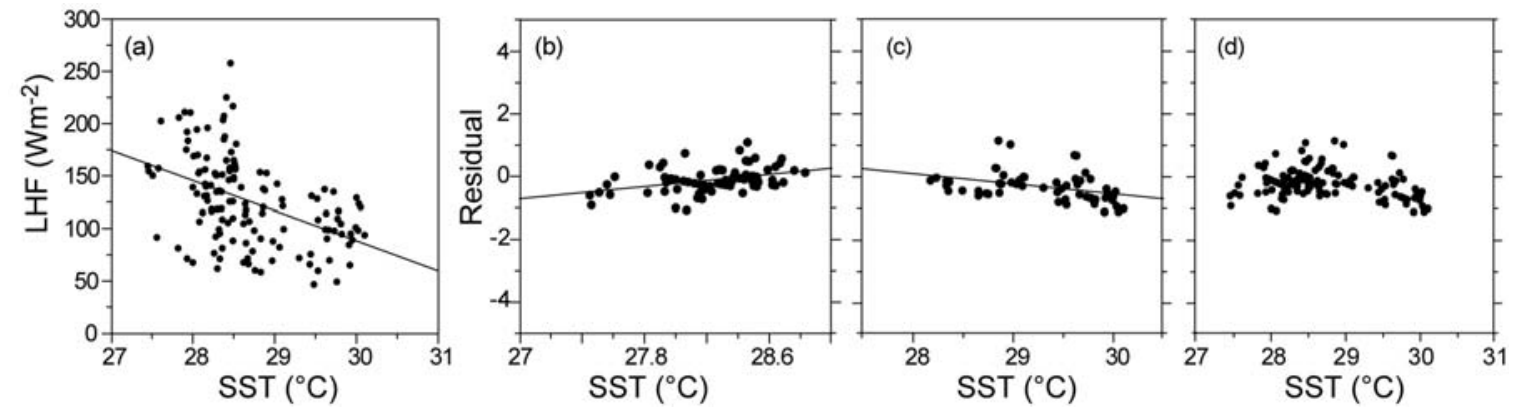

Fig. 4. Scatter plots for SST Vs LHF (a). Residuals Vs SST during summer (b), fall(c) and for both situations (d). 